\title{
Research on the Reform of Course Assessment and Evaluation in Col- leges and Universities
}

\author{
Zhiwen Zhu ${ }^{*}$ \\ Shandong University of Technology, Zibo, Shandong, 255000, China
}

\section{ARTICLE INFO}

Article history

Received: 1 April 2021

Revised: 7 April 2021

Accepted: 9 April 2021

Published Online: 16 April 2021

Keywords:

College curriculum assessment

Evaluation reform

Process evaluation

\section{Introduction}

College Students' learning evaluation is based on the professional training objectives as a reference to assess and evaluate the learning level of students in the aspects of knowledge mastery, ability formation and quality cultivation $^{[1]}$. As an important link in the process of talent cultivation, learning evaluation is of great significance for testing the implementation of the syllabus of each course, ensuring the teaching quality and promoting the cultivation of students' comprehensive quality.

On October 31, 2020, the fourteenth meeting of the Central Committee for comprehensively deepening reform deliberated and approved the "overall plan for deepening education evaluation reform in the new era", which first proposed the new concept of "four evaluations" of

\begin{abstract}
Under the background of the new concept of "four evaluations", colleges and universities need to strengthen the management of learning process, promote the reform of curriculum process evaluation, build a diversified student learning evaluation system, reflect the achievement of curriculum objectives, timely feedback and form continuous improvement. This paper discusses the necessity of the reform of college curriculum evaluation, interprets the concept of the new concept, and puts forward the implementation method of the evaluation reform, in order to contribute to the reform of college curriculum evaluation.
\end{abstract}

"improving result evaluation, strengthening process evaluation, exploring value-added evaluation, and improving comprehensive evaluation". At the same time, according to the requirements of "general standards and interpretation of engineering education professional certification (2020)", and guided by the three basic concepts of engineering education professional certification: "outcome oriented", "student-centered" and "continuous improvement", a formative evaluation mechanism should be established.

\section{The Disadvantages of the Existing Course Assessment Methods}

\subsection{Examination Implementation}

At present, most of the university curriculum assess-

\footnotetext{
*Corresponding Author:

Zhiwen Zhu,

Doctor's degree from Shanghai University of Finance and Economics;

Lecturer in school of mathematics and statistics of Shandong University of Technology;

Research direction: economic statistics;

E-mail:mengchen264@126.com.
} 
ment is a one-time end of the examination, at the same time, combined with the usual results to give the total score. The average score is $20 \%$, and the exam score is $80 \%$. The average score mainly includes attendance and homework. The main goal of this kind of course assessment method is to check the students' learning effect and make the final assessment, but it ignores the evaluation of students' learning process and the assessment of students' ability and quality ${ }^{[2]}$. It leads to the lack of formative evaluation, and the function of detection and diagnosis, feedback and improvement of teaching process operation quality can not be played in real time.

\subsection{Examination Form}

Most colleges and universities tend to the theoretical paper and pen examination, which makes it difficult for students to effectively test the experimental and practical skills in class.

\subsection{Examination Proposition}

Most colleges and universities still stay in the stage of empirical proposition, which is difficult to ensure that the coverage of knowledge content and the level of ability objectives and their proportion conform to the provisions of the syllabus ${ }^{[3]}$. It can not reflect the achievement of the curriculum objectives and guarantee continuous improvement.

\subsection{Examination Content}

Most courses focus on the examination of low-level teaching objectives, which leads students to memorize hard, which is not conducive to the comprehensive use of knowledge and hinder the cultivation or formation of students' multiple abilities.

Therefore, colleges and universities should strengthen the management of learning process, track and evaluate the performance of students in the whole learning process, and ensure that the students can complete the curriculum objectives in the curriculum standards through process evaluation, and then meet the graduation requirements of students; strengthen the examination management, strictly pass the assessment, increase the proportion of process assessment results in the total course scores; improve the ability and knowledge The multi chemical industry assessment system with equal emphasis on assessment should be applied to improve the monitoring, evaluation and feedback mechanism of students' learning process $^{[4]}$.

\section{A Conceptual Interpretation of the New Concept of Evaluation Reform}

The "four kinds of evaluation" model proposed in the overall plan is highly innovative, which greatly enriches the theoretical research of education evaluation in China and lays the foundation for the formation of the theoretical framework of education evaluation system with Chinese characteristics.

Result evaluation is a result oriented evaluation model, which is used to measure the extent to which educational goals and tasks can be achieved or completed. From the technical point of view, there is no problem in the result evaluation itself, but if the goal and task of result evaluation are unreasonable and unscientific, it will inevitably lead to poor evaluation effect.

Process evaluation is a value judgment which focuses on the changes in the development process of evaluation objects $^{[5]}$. Its characteristics are: (1) process evaluation is a process of constructing the value of learning process; (2) process evaluation is completed in the learning process; (3) process evaluation emphasizes the proper participation of learners; (4) process evaluation is a process of promoting the development of learners.

Value added evaluation is a kind of evaluation method to evaluate the progress of evaluation objects. It has changed the tendency of school evaluation in the past to pay more attention to the education process, and to explore and realize the evaluation reform of promoting teaching and learning by evaluation.

Formative assessment refers to observing and evaluating students' learning state in various ways in the course of teaching, finding problems, correcting or helping students to achieve the course objectives in time. The purpose of evaluation is to improve teaching and make as many students as possible meet the graduation requirements at the end of their studies.

\section{The Implementation Method of Evaluation Reform}

\subsection{Curriculum Objectives}

According to the requirements of the syllabus and the latest curriculum evaluation system, we revise the syllabus. To meet the following requirements of the evaluation of the achievement of curriculum objectives:

(1) There are clear quality standards: syllabus, reaching standards;

(2) Reasonable evaluation basis: teaching plan, test paper, report, etc;

(3) There are scientific evaluation methods: qualitative 
and quantitative evaluation methods;

(4) There are complete evaluation records: evaluator, result, improvement.

\subsection{Different Stages of Evaluation}

Three different stages of evaluation were carried out $^{[6][7]}$. Teachers need to give feedback to students in time after the evaluation to ensure the formation of continuous feedback to improve teaching

(1) Examination at the beginning of term -- diagnostic evaluation

To understand the students' mastery of the previous teaching content and the possible obstacles to learning new knowledge;

Find out if students have the foundation and skills to accept new knowledge, and what their learning potential is.

(2) Midterm examination -- process evaluation

Understand the students' mastery of teaching content and skills in each stage, find out the weak links in students' learning, and provide feedback information for future teaching.

(3) End of term examination -- summative evaluation

The purpose of this paper is to comprehensively check the students' learning effect, understand the students' understanding, mastery and application of the course content, identify whether the students have reached the requirements of teaching objectives, and provide information for teachers to improve teaching in the future.

At the end of the course, teachers should fill in the evaluation results of the above three stages, and the proportion of summative evaluation should be controlled at $30 \% \sim 60 \%$.

\subsection{Chapter Test or Unit Test}

In the stage of process evaluation, chapter test or unit test should be arranged according to the teaching schedule

(1) Enrich the evaluation subject, emphasize participation and interaction, and advocate the combination of self-evaluation and other evaluation. The process evaluation can be divided into four categories: Students' self-evaluation, students' mutual evaluation, teachers' comments and enterprise evaluation. Among them, enterprise evaluation is mainly for practical courses, and it is suggested to guide enterprises to participate in student evaluation. The purpose of student self-evaluation and peer evaluation is to make students become a member of the evaluation subject, emphasize participation and interaction, promote their active participation, self-reflection, self-education and self-development, so as to stimulate students' learning enthusiasm and improve learning efficiency.

(2) In terms of specific evaluation methods, group discussion, classroom questioning, classroom presentation, individual homework, case analysis, research report, debate speech, model making and other methods can be adopted according to the characteristics of the course to encourage innovative forms. Based on the needs of students' development, through the whole process of students' learning and development, through the continuous collection of key information and data in the process of students' learning and development, we can timely judge the advantages and disadvantages in the process of their development.

(3) In terms of assessment methods, you can choose open book, closed book, interview, semi open book, investigation report, paper design or online test, etc. through a variety of methods to enrich the connotation of assessment, the assessment will be changed from a single closed book test to a multiple open test. Meanwhile, the standards of relevant assessment methods will be formulated in the assessment process to ensure the quality of assessment and stimulate students' interest in learning, so as to improve students' physical fitness now we have the advantages of autonomous learning.

(4) Type requirements

In the design of test questions, we should adapt to the goal of applied talents training, strengthen the evaluation of practical ability and innovation ability of combination of knowledge and practice, emphasize the participation and subjectivity of students, advocate research-based testing, encourage the innovation of evaluation methods, make the assessment from a single closed book test into a multiple open test, stimulate students' interest in learning in the assessment process, and reflect self-learning the advantages of learning.

On the basis of course group and experts' argumentation, the evaluation questions are scientifically designed. In addition to the traditional multiple-choice questions, fill in the blanks, judgment questions, discrimination questions and short answer questions, the open-ended questions such as discussion questions, design questions, data analysis questions and case proof questions are often used to encourage innovation. Increase the knowledge and coverage of examination questions, ensure the reliability, discrimination, difficulty, average score and standard deviation of examination questions, and scientifically and objectively assess the quality of teaching and learning.

\section{Conclusion}

In order to smoothly promote the reform of the evalu- 
ation mode of university curriculum, we must realize the transformation from administrative evaluation to professional evaluation ${ }^{[8]}$. To strengthen process evaluation, to explore value-added evaluation and to improve comprehensive evaluation, each link will face a common problem, that is, how to ensure the objectivity, impartiality and credibility of evaluation. To carry out process evaluation and multiple evaluation, the key is to break through the single quantitative evaluation system and introduce other growth index factors to evaluate the students' growth process. On the operational level, professional evaluation is needed, which is also the biggest difficulty of the reform.

\section{References}

[1] Niu Lianqiang, Feng Haiwen. Reflections on the development of formative evaluation of University Curriculum Teaching -- Based on the background of engineering education professional certification $[\mathrm{J}]$. University education, 2017 (09): 192-195.

[2] Ma luting, Wang Xiaomei, Liu Fuxing, Zhou Guangli, Shi Xiaoguang. Deepening the reform of education evaluation in the new era $[\mathrm{J}]$. China higher education research, 2020 (11): 1-6.

[3] Chen Zhongtang, Liu Dan, AI Ying, AI Jie. Research on curriculum assessment method based on students' learning process evaluation with ability as the core
[A]. Liaoning higher education society. Collection of excellent papers of Liaoning Higher Education Society 2017 academic annual meeting [C]. Liaoning Higher Education Society: Liaoning Higher Education Society, 2017:7.

[4] He Chunmei. Process evaluation, achievement goal orientation and learning engagement: mechanism and path [J]. Exploration of higher education, 2020 (11): 36-46.

[5] Liu FengChen, Zhang Yajiang, Qian Bingyu, Xiao Kun, song Zuozhong. In order to evaluate students' learning effectiveness, we should strengthen the research on the reform of curriculum assessment methods [J]. Economist, 2013 (02): 133 + 135.

[6] Zhang Haojun. On the reform of college curriculum assessment method based on formative evaluation $[\mathrm{J}]$. University education, 2018(07): 180-182+192.

[7] He Jiji, he Yu, Liu Jiangcheng, Wan Qiang, Wei Liang. Problems and continuous improvement strategies after curriculum examination reform in Application-oriented Universities [J]. Industry and Technology Forum, 2020,19 (23): 270-271.

[8] Liu Nan, Yu Junwei. Reform and practice of learning effectiveness oriented curriculum assessment method [J]. Journal of Jiamusi vocational college, 2015 (06): $151+153$ 